\title{
Hypengyophobia: The Missing Vulnerability In Addiction Recovery
}

\author{
Mary J. Didelot, Ph.D. ", Lisa A. Hollingsworth, PsyD \\ Associate Professor of Education, Purdue University Northwest, United States.
}

\author{
Article Details \\ Article Type: Review Article \\ Received date: $01^{\text {st }}$ October, 2021 \\ Accepted date: $25^{\text {th }}$ October 2021 \\ Published date: $27^{\text {th }}$ October, 2021
}

"Corresponding Author: Mary J. Didelot, Ph.D., Associate Professor of Education, Purdue University Northwest, United States. E-mail: mjdidelo@pnw.edu

Citation: Didelot, M.J., \& Hollingsworth, L.A. (2021). Hypengyophobia: The Missing Vulnerability In Addiction Recovery. $J$ Ment Health Soc Behav 3(2):149. https://doi.org/10.33790/jmhsb1100149

Copyright: $\mathbb{C} 2021$, This is an open-access article distributed under the terms of the Creative Commons Attribution License 4.0, which permits unrestricted use, distribution, and reproduction in any medium, provided the original author and source are credited.

\begin{abstract}
Within the clinical work of professionals in the field of addictions, co-existing vulnerability factors are rampant. One impactful vulnerability which is seldom recognized by professionals but significantly effects an individual with addictions and his/her perception of the self and others is hypengyophobia. This is a fear of responsibility. Yet, taking responsibility in addiction is a major theme for healing. A life of passivity will not lead to recovery, and this is exactly the effect of hypengyophobia. Grounded in Jung's (1933) psychodynamic theory, with a case study example included, understanding, recognition and an innovative treatment for this rarely explored vulnerability is forwarded to clinical professionals in addictions. Hypengyophobia is forwarded as an integral part of addictions' treatment.
\end{abstract}

\section{Introduction}

Within addiction, there are a plethora of co-existing vulnerability factors, such as fears, which can both interfere and complicate treatment while depleting internal personal resources for adults. These are considered risk factors in the recovery process. It is accepted that "those who feel unable to control events in their lives will respond passively" (p.555), thus the birth of vulnerabilities for people with addictions. Not only can these vulnerabilities negatively affect the person suffering with addictions, but these matters can negatively affect family members, friends, and professional colleagues' perception of the individual. Addiction itself frequently co-exists with other issues that prompt revisions in treatment regimens to recognize the nuanced psychological factors sophistication of the phenomenon.

One distal risk factor, which is extant and impacting, yet seldom recognized as a vulnerability that increases SUD risk is hypengyophobia, or a fear of responsibility. Those who are addicted, and their families do not fully understand the reach of hypengyophobia are not completely understanding their own risk factors in the recovery process. This actuality is maladaptive and can be overwhelming to a person with addiction.

\section{Hypengyophobia}

For many with addiction, life itself can be viewed as one crisis after another. For those with hypengyophobia, it is a life of passivity; of the perception of unapproachable responsibilities and an underlying fear of decision-making that fuels the addictive process at the expense of self and others. Internally, it is crippling. Yet, from others, it may be perceived as self-indulgent or immaturity, because it does concomitantly put the responsibility of the addicted individual's life on others, especially loved ones. The person with the addiction who is suffering with hypengyophobia is simply never perceived by others as an adult. Interestingly enough, there is child-like thinking that prevails. That thinking, as encoded in childhood and identified by Hollis [1], found "The world is an encoded message to me, a statement about me, about how I am valued, and how I am to comport myself. Another way of putting this is: I am what happens, or happened, to me" (p. 106). This belief can haunt us from our childhood at an unconscious level. Applying Firestone [2] findings to any fear in addictions, it "may render us emotionally immature and often, far less functional" (p. 2). The individual experiencing this external maladaptive behavior lives in a world of perdition, as hypengyophobia only serves to amplify addiction.

Hypengyophobia may cause a regressive process when it comes to adult responsibilities. Personal integrity is lost. Not only does this form the foundation for distorted perceptions from those working with the person, but the person with the addiction him/herself looking inward, leading to maladaptive actions and thoughts, chronic conflict with self and others, misinterpretation of relationships, psychic energy fatigue, and a complete reliance on others for decisionmaking. The symptoms may vary when confronting a responsibility. The symptoms may also skew any cogent responses by the person. These factors generate an increase in addictive behaviors and substance use. Thus, hypengyophobia also interferes with the ability to enter recovery and sustain maintenance.

Further, the literature of addiction is replete with the referrals to people with addiction as "children" or "dependent". Hypengyophobia, which would offer a logical and sound explanation for these referrals and their behavioral ramifications, is rarely and poorly articulated with the literature. Yet, the fear of taking responsibility for decisions can accelerate the drive to self-medicating with substances.

\section{Vulnerabilities}

"Addictive behavior is a result of a primal desire to self-soothe" according to Firestone [2] (p. 1). This effect creates a fertile ground for the development of vulnerabilities. It is universally accepted that those who are diagnosed with substance use disorders (SUD's) are vulnerable in the areas of:

- Ego deficiencies that cause cognitive and emotional distortions and movement toward psychological dependency,

- Dependency that causes those with SUD to be vulnerable in interpersonal interactions through their attempt and successes in manipulation and neediness, 
- A lack of responsibility for their own actions or non-action that includes no responsibility for consequences, and

- $\quad$ Self-concept deficits cause self-loathing and despair, which then may find compensation in what is perceived as narcissism [3].

From these, the concept of hypengyophobia is clearly absent, yet it may play into each of these. It is posited here that in addition to the four universal vulnerabilities identified by Hussong, Jones, et. al, [3] that hypengyophobia be added as a fifth vulnerability. Further, hypengyophobia plays an important role in the fears that surround addiction. Two frequently cited and significant fears in addiction are change and reality. This makes sense considering both involve taking responsibility for actions taken or not taken. Since addiction may be viewed as an archaic desire to self-soothe psychic pain, helping a client to help himself becomes a Herculean task. Add hypengyophobia to the mix, and the level of difficulty exacerbates, as does the pain and suffering. "Our attempts to cut off [pain] may render us emotional immature and often, far less functional" (p.7) [4].

According to the American Medical Association [5], there are factors of cognition that have the propensity to effect perception and behavior significantly, yet do not fit with the DSM-5 criteria for diagnosis and designation as a pathology (Cheadle, 2021). These factors can also affect therapeutic interventions. In applying this to addiction, it is put forward that these facts may also be directly applied to hypengyophobia as it effects vulnerabilities.

Additionally, it is accepted that pain may cause maladaptive behaviors such as catastrophizing and helplessness, resulting in an adult with addiction to both perceive him/herself and be perceived as immature. As can be reasoned, hypengyophobia threads itself through the vulnerabilities and fears of individuals with addiction. By understanding and realizing the role this phenomenon plays in addictions counseling, professionals may be better equipped to help individuals at a foundational level to facilitate healing.

\section{Jung: A Theoretical Foundation}

To further explain the psychodynamic nature of hypengyophobia, Jung's [6] theories will be employed as identified by Hollis [7]. Hollis, in an extensive practical application of Jung's teachings, explains, "in the end, we all fear two things, two categories of existential vulnerability: the fear of overwhelment and the fear of abandonment" (p. 28). Existentially, hypengyophobia disconnects us from living. It is clear that the ego drives these fears. It is argued that it is within this context the hypengyophobia resides, feeding Jung's shadow self, deprives an individual of energy to be assertive and make choices. The shadow has those with hypengyophobia believing in avoidance because of responsibility for making decisions. Jung would view this as a neurosis, and, as Hollis [7] would conclude, "neurotic is a problem to him/herself, and personality disorder is a problem for others" (p. 183).

Hollis [1] offers further depth and breadth to his Jungian theoretical approach toward addictions or what he considers the "anesthetizing of the consciousness" (p. 340). Hollis has also described addiction as a "self-treatment" plan, which perfectly meshes with a person's self-soothing drive at the heart of addictive behavior (p. 64). He also encourages individuals to "face the patterns of addiction...to [have] any sense of hope of growth" (p.341). These insights by Hollis get to the heart of hypengyophobia: Once an individual looks to the patterns created by the fear, the door to healing can be unlocked.

This collapse is that which Jung [5] has termed the regressive restoration of the persona. There is a total collapse in conscious decision-making and forward movement in life. Therefore, they experience a major collapse of the self. Also, there is a perceived security in addictive affect, behavior, and cognition. It explains the perception by others that the person with an SUD and hypengyophobia does not consciously want to move forward when the person is afraid to move forward into recovery. Additionally, this exacerbates the addiction, making those suffering appearing to be irresponsible children taking no responsibility whatsoever, especially for their drug use and recovery.

\section{The Effects of Hypengyophobia on Recovery}

There are two models of best practice that are endorsed by the Substance Abuse and Mental Health Services Administration (SAMHSA) [8] of the federal government, the recognized source of factual information and current research in the U.S. These models have withstood the test of time and are still the most used and respected models. The first model is DiClemente, Prochaska \& Fairhurst's et al. [9] Stages of Change (1991) and the FRAMES model of Miller and Sanchez [10]. The first questions, however, is how does hypengyophobia play into the recovery process and why is this such a dangerous vulnerability during the process?

DiClemente, Prochaska \& Fairhurst, et al. [9] identified the five stages of change for recovery during their research on smoking tobacco. This is a pure recovery model that puts the choice for follow-through and all responsibilityis on the individual. These are not linear. They are:

- Precontemplation: This is the stage of denial. The individual does not recognize that their SUD is problematic. Responsible action, including decision-making, for the individual are nil at this point. During this stage, hypengyophobia may not be noticed.

- Contemplation: Although the individual realizes the problems the SUD is causing, there is still an overriding significant uncertainty for change. There is still no responsible action, decisions, taken at this stage. Again, hypengyophobia may not yet be identified.

- Preparation: The individual commits to the lifestyle change of recovery. Responsibility must be taken, and the decision is made to go into recovery. An individual with hypengyophobia would not be able to even approach discussion of Preparation.

- Action: The person creates a step-by-step plan for change. This stage requires responsibilities in all areas of the individual's life. This step could not be taken by an individual with hypengyophobia.

- Maintenance: The plan for action is followed and a support system is nurtured. The individual must be responsible constantly and consistently. Hypengyophobia would block this advanced progress at every juncture, and

- Relapse (a recently added stage that was concomitant with formal recognition of relapse as a part of the disease of addiction): A regression back to using occurs. This is a regression to total fear of responsibility; to hypengyophobia.

The FRAMES model is another popular and successful approach to recovery. This was created as a brief therapy for alcohol addiction [10]. It is also considered a motivational model for lifestyle change from a person with addictions to a person without addictions:

- Feedback: In this phase, a professional assesses the individual for SUD, gives the individual the results, and the individual recognizes those results. There is no responsible action needed for this phase. The individual is not asked to take the responsibility of accepting the results, just recognizing them.

- Responsibility to change: The individual makes and commits to change. This requires the individual to decide if he/she is going to be responsible to him/herself for the rest of their lives. The effect of hypengyophobia would devastate this phase of recovery and put a hard stop on recovery efforts. 
- Advice about changing: The professional gives the individual information about the SUD(s). No effort toward responsibility is needed here by the individual.

- Menus of self-directed change: The individual creates options by identifying alternative actions/activities from addictive actions/activities. Hypengyophobia would cripple the individual from even initiating this task.

- Empathetic counseling: The professional demonstrates compassion for the individual's suffering. Hypengyophobia would have no effect.

- Self-efficacy: The professional and the individual debunk powerlessness. An individual with hypengyophobia would never take on this responsibility.

As can be deduced, these models are both highly dependent on the ability of the person with SUD to take responsibility for their own actions with constant decision-making as their life circumstances consistently change. When a person has hypengyophobia in addition to SUD's, it is important in treatment to address the hypengyophobia while integrating it with addictions' services.

Underlying these models is the nature of the recovery process requires, at minimum, the following affirms the responsibility, autonomy and decision making required for recovery as identified by SAMHSA [8]. The individual with SUD's would, in order to recover, demonstrate and practice the following:

- Affirm the autonomy and decision-making

- Action based on determination to go into recovery

- Decision to change negative behavior

- Reinforce positive actions

As recommended by SAMHSA, these four actions are necessary for an individual to recover, yet, when a person with SUD has hypengyophobia is nearly impossible to even encourage them to take these actions, none the less begin treatment toward recovery, because that would be asking the client to take responsibility.

The four actions above form the foundation for both recovery models. Along with these four actions are the five types of resistance found in individuals with SUD's that also need to be considered when using the models: arguing, interrupting, denying, and ignoring. Of these denying is the resistance most impacted by hypengyophobia. It is important because denial is "predictive of poor treatment outcomes and lack of involvement" (p. 46). One of the key factors in denial is the acceptance of responsibility, which is not possible in a person with hypengyophobia. The hypengyophobia must be managed first.

\section{A Case Study}

The following is a case study of a woman suffering from addictions for the last three years. It is an example of the crippling and exacerbating effects of hypengyophobia upon a person with an SUD.

Gina (pseudonym) is a 52-year-old woman who sought therapy for addiction, depression, and "grounding" because, as indicated at her first session, "I don't know what I'm doing". Therefore, Gina "cannot make a decision". She then becomes "irrationally angry".

Currently, Gina is single, living in her now deceased parents' home. She has "always" lived there, meaning it is the home in which she grew up and continues to live there. She knows no other residence. She also resided at this home while in community college. Both parents died within 3 months of each other. Upon the death of her parents three years ago, who she identifies as her "best friends", Gina increased her drinking to a harmful, addictive level. Alcohol was her drug of choice.

Although she is intoxicated most of the time, she says she is a "functional drunk" able to maintain her job because she does work remotely and independently in her project- based career. Gina selfreports that her consumption of alcohol is increasing to the point of brownouts, and a new symptom: She is "crippled by her inability to take responsibility for herself and leftover family matters from her parents' estates."

This feeling identified by Gina is echoed throughout each session. She reports that when she allows herself to think of a responsibility, she drinks more to blunt her suffering, and forget about the decisions she needs to make. She "binges a lot". She reports she cannot "get a handle" on the drinking. In fact, she likes it. It makes her "forget".

Gina's inability to take responsibility is building for her and the pressure from her family to make decisions is increasing almost daily. There are very few days when Gina does not get a communication from family, close friends, lawyers, and accountants to take on the following existing open responsibilities:

- Memorial ceremony: In her parents' wills, it was specifically stated that they were to be privately cremated and separate memorial ceremonies for family and friends were to be held. Three years later, their urns remain in a Gina's closet, and relatives, friends, and lawyers continue to "hound" Gina.

- Gina's parents' taxes have remained unsorted and unpaid since the year 2010, when, as Gina is informed regularly by the accountant, that her father has not filed since then. No action can be taken on the trust her parents left with the attorney until this is done.

- Gina mentions every session that the house makes her ill and causes her to drink because of all the horrible memories of both her parents dying there. She cannot bring herself to go into her parents' bedroom. She closed it off immediately from the rest of the house upon her mother's death because it "haunts" her. However, she must pass the door constantly to go into the kitchen. Gina "needs" to sell the house, but she "can't", because "I can't take that responsibility. I'm frozen." She understands she would be required to first take responsibilities of the taxes, trust, and removal of furniture, etc., involved in getting a home ready for sale.

- Gina also knows she needs to move, but again, "every time I think about it, I just start drinking, then I don't have to think about it. When I wake up from my stoper, I have forgotten all about another "have to do." She describes this as a "permanent sticking point".

- An additional point of the fear of responsibility involves Gina's dog. Her dog, "who is the only person I have who loves me", has been diagnosed with a tumor, which may be causing some side effects for the medical issues the dog is experiencing. This tumor was found right before her parents' death. It was suggested by veterinarians to keep a close eye on the tumor's growth or shrinkage. Gina cannot take the responsibility to have the dog rechecked because "that would mean I would have to take the responsibility of walking my dog on grass that may have been fertilized which causes cancer."

Gina's case is a prime example of a client with signs and symptoms of hypengyophobia. It is very evident how this fear of responsibility is driving her alcoholism, including her distorted cognitions, perceptions, and behaviors. Without treatment for hypengyophobia, Gina will stagnate in an alcoholic state. She cannot move to and through recovery without addressing this vulnerability.

\section{Treatment Guide}

Hypengyophobia is the fear that drives others to perceive the adult as immature and causes a riveting fear for the individual suffering from it into a state of immaturity and irresponsibility, which increases the consumption of alcohol and drugs. In order to treat this vulnerability, 
it is suggested that the following steps be taken. This is a linear treatment with each stage dependent on the previous stage.

Using the case study of Gina, the phases of the guide can lead any health professional to successful prepare an individual for recovery or support an individual's recovery effort. How does this treatment apply to Gina?

1. Understand what hypengyophobia is and how this effects a person with SUD. It is extremely important for any health professional who works with individuals with SUD to be knowledgeable of this vulnerability that can undermine recovery.

2. Recognize this phenomenon in the individual. Gina herself blatantly uses the language of hypengyophobia: ": "responsibility", "cripple", "can't move," "sticking point," "hounded", "frozen", and "have to do, but can't start." She also has not taken any action in three years as her drinking has increased in those years.

3. Theoretically relate this $(\# 1,2)$ to the individual. Gina would realize by hearing a professional clearly, firmly, and compassionately use her own words so she can realize how hypengyophobia has affected her: not taking responsibility for the remembrance, taxes, trust, house, and dogs. It also would be wise to point out how these unmet responsibilities are inhibiting her living a full life and driving her drinking.

4. Break the exploration of this into manageable parts. Each part must be taken to its lowest common denominators. For example, look to the remembrance ceremonies. This could be explored by discussing parents' wishes, place, time, guests, invitations, minister, costs, etc.

5. Explore each part with the emphasis on how each has caused maladaptive, irresponsible cognitions, perceptions, and behaviors. For Gina, with her dog, a good starting point with her dog would be some medical education on tumors to stop her spiraling thoughts that it must mean the dog will die and her other constant thought is "that if I take the dog to a vet, she will die." This will start to ease the maladaptive emotions.

6. Develop a menu, with the individual, for action (healing). Using the dog again, from the information found in \#5, develop a list of several actions she can take. Make sure they are small actions, not go to the vet, but find a vet who works with tumors.

7. Have individual choose a responsible action. With the professional, choose the vet and make the phone call for an appointment while in the office. The individual is asked to put the appointment in her phone or planner in front of the professional. She is asked to text the professional on the day of the appointment, and after the appointment with short messages of compliance.

8. Have the individual practice the responsible action. Role play the discussion, for example, with the vet. Develop questions and concerns.

9. Evaluate through realization of success or failure. Explore the event in detail, paying attention to coping skills or coping skills which need to be developed.

\section{Conclusion}

"Maladaptive cognitions have the quality of being automatic and habitual so that they are rarely examined for validity" . Hypengyophobia fits into this statement. It is rarely recognized or explored, but it is far reaching in the damage it does to a person with addictions who is attempting recovery. The fear of responsibility distorts cognitions, perceptions, and behaviors that have already been ravaged from the effects of SUD's. Thus, it is posited here that hypengyophobia become an integral part of addictions treatment.
Conflict of interests: The authors declare no conflict of interest.

\section{References}

1. Hollis, J. (2005). Finding meaning in the second half of life. New York: Gotham.

2. Firestone, L. (2021). Is fear of emotion driving our addiction? Retrieved August 29, from psychalive.org/fear-emotiondriving-addiction/

3. Hussong, A.M., Jones, D.J., Stein, G.L., Baucom, D.H. \& Boeding, S. (2011). An internalizing pathway to alcohol and substance use disorder. Psychol Addict Behav (3) 390-404.

4. Goodman, S. (2019). Psychodynamic approach to addictions treatment. Th Biopsychosocial model revisited. Retrieved August 28, 2021 from researchgate.net

5. Cheatle, M.D. (2021). Psychological issues in the management of pain. In Herron, A.J. \& Brennan, T.K. ASAM Essentials of addiction medicine. New York: Wolters Kluwer.

6. Jung, C.C. (1933). Modern man in search of a soul. New York: Harcourt, Brace, \& World.

7. Hollis, J. (2009). What matters most. New York: Gotham.

8. Substance Abuse and Mental Health Administration. (2013). Enhancing motivation for change in substance abuse treatment. Treatment improvement protocol. TIP 35. Rockville, MDU.S. Department of Health and Human Services.

9. Di Clemente, C.C., Prochaska, J.O., Fairhurst, S.K., Velicer, W.F., Velasquez, M.M. \& Rossi, J.S. (1991). The process of smoking cessation: an analysis of precontemplation, contemplation, and preparation stages of change. J Consult Clin Psychol, (59) 295-304.

10. Miller, W.B. \& Sanchez, V.C. (1994). Alcohol use and misuse by young adults. In Motivating young adults for treatment and lifestyle changes (pp. 58-81). Notre Dame, IN: U of NDPress. 